J. Lake Sci. (湖泊科学) , 2016, 28(5): 1134-1140

DOI 10. 18307/2016. 0524

(c) 2016 by Journal of Lake Sciences

\title{
栅格新安江模型在天津于桥水库流域上游的应用"
}

\author{
黄小祥 ${ }^{1}$, 姚 成 ${ }^{1}$, 李致家 ${ }^{1}$, 谢润起 ${ }^{2}$, 于福民 ${ }^{2}$, 张 强 $^{2}$ \\ (1: 河海大学水文水资源学院, 南京 210098) \\ (2: 天津市水文水资源勘测管理中心, 天津 300060 )
}

\begin{abstract}
摘 要: 栅格新安江模型是在概念性新安江模型的理论基础上,以栅格为计算单元, 结合地形地貌和下垫面特性构建出 来的水文模型. 在于桥水库流域上游的水平口流域应用栅格新安江模型,研究该地区洪水要素的空间变化以及洪水形成 过程,讨论洪水模拟效果来验证模型在半湿润地区的适用性. 选取水平口流域 1978-2012 年的洪水进行模型计算, 模拟 结果较好地反映了流域产流面积的时空变化, 且均达到乙级以上精度. 初步表明栅格新安江模型在半湿润地区有较好的 适用性.
\end{abstract}

关键词: 栅格新安江模型;产流面积变化;洪水模拟;于桥水库;水平口流域

\section{Application of grid-Xinanjiang model in the upstream of Yuqiao Basin, Tianjin}

\author{
HUANG Xiaoxiang ${ }^{1}$, YAO Cheng ${ }^{1}$, LI Zhijia ${ }^{1}$, XIE Runqi ${ }^{2}$, YU Fumin ${ }^{2} \&$ ZHANG Qiang ${ }^{2}$ \\ (1: College of Hydrology and Water Resources, Hohai University, Nanjing 210098, P.R.China) \\ (2: Tianjin Municipal Administrative Center of Hydrology and Water Resources, Tianjin 300060, P.R.China)
}

\begin{abstract}
Grid-Xinanjiang hydrology model used in this study is a spatial grid-data processing model which combines theory of the conceptual Xinanjiang model with different kinds of analysis on DEM, soil type and land cover data. We applied the model in Shuipingkou Reservoir located in the upstream of Yuqiao Basin to study the spatial variation of flood factors and the flood procedure in a semi-humid region. The simulation experiment based on the data ranged from 1978 to 2012 , and we analyzed the flood simulations to check the applicability of this model in semi-humid regions. The simulation results turned out to be satisfied that showed significant changes of runoff producing in various areas of the basin, suggesting that the model has the potential in space to be adaptable for the semi-humid regions.
\end{abstract}

Keywords: Grid-Xinanjiang model; change of areal runoff producing; flood simulation; Yuqiao Reservoir; Shuipingkou Basin

数字水文学和数字水文模型技术的发展得益于 DEM/DTM 技术的提出和遥感以及计算机等技术的发 展 ${ }^{[1]}$. 通过 DEM 地形数据可以便捷地提取出流域边界以及流域内的河网水系. 利用遥感地貌数据则能分析 出流域土壤植被的空间分布情况. 以单元水文理论为基础, 流域空间数据作为支撑的基于 DEM 的水文模型 是当前水文模型发展的方向, 也是水文模拟技术研究的热点 ${ }^{[2]}$. 基于 DEM 的水文模型既能反映水文循环的 时空变化,也能模拟自然条件变化以及人类活动对水文循环过程的影响.

国内基于 DEM 的水文模型研究很多 ${ }^{[3-7]}$. 栅格新安江模型是基于 DEM 水文模型的一种 ${ }^{[8]}$. 栅格新安江 模型以栅格为计算单元, 以三水源新安江模型为理论基础, 以地形数据、植被覆盖和土壤类型作为参数空间 分析依据. 该模型在湿润地区有着理想的应用效果 ${ }^{[9-11]}$. 本文选取天津于桥水库流域上游的水平口流域作 为研究对象. 选取流域 1978-2012 年内的洪水做模拟预报研究, 对模型结构参数率定以及洪水要素的空间 变化进行讨论, 探究模型在半湿润地区的适用性.

* 国家自然科学基金项目 (41130639, 51179045)、水利部公益项目 (201501022, 201301068) 和淮河流域气象开放研 究基金项目 (HRM201404) 联合资助. 2015-10-29 收稿;2015-12-09 收修改稿. 黄小祥(1992 ), 男, 硕士研究 生;E-mail:1239124925@qq.com. 


\section{1 流域概况}

\section{1 自然地理}

水平口流域 (图 1) 面积 $799 \mathrm{~km}^{2}$, 主河道长 $69.5 \mathrm{~km}$, 平均坡度 $13.9 \%$. 沙河是流域内干流, 呈扇状. 河流 呈现季节性特征, 上半支在汛期外基本呈干枯断流状态, 下半支常年有水. 流域内大部分地处山区、半山区, 流域内海拔高度由北向南递减. 现有的森林植被都是天然次生林和人工林, 主要分布在山地丘陵地区. 土壤 主要是潮褐土.

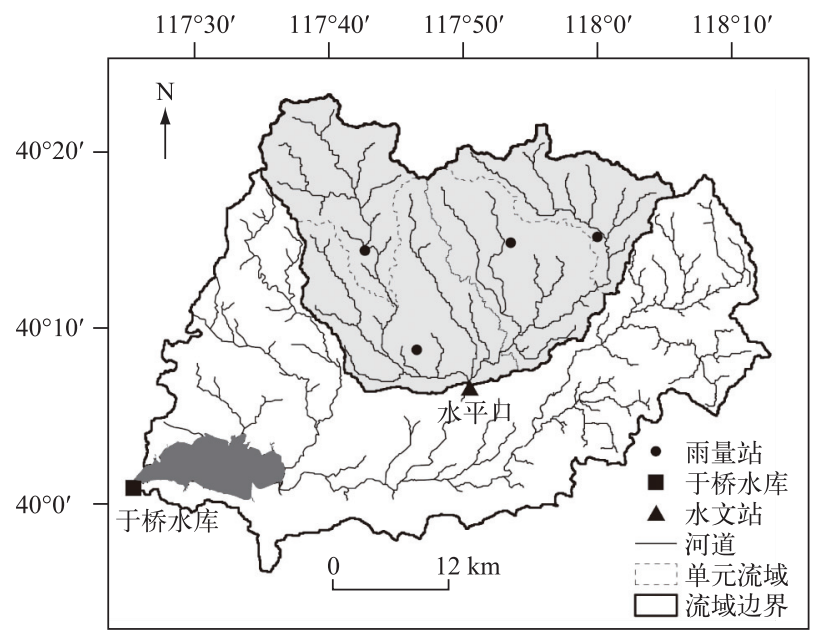

图 1 水平口流域内水系及站点分布

Fig.1 Distribution of rivers and stations in Shuipingkou Basin

\section{2 水文气象}

水平口属于暖温带半湿润大陆性季风气候. 流域内的雨量集中,雨热同季. 降水年内分布不均,夏季多 达 67\% 76\%. 流域内的降水由北向南递减,多年平均降水为 700 750 mm.

\section{3 数据资料}

雨量资料为 1978-2012 年间遵化等站的逐日降水量和降水量摘录; 蒸发资料为水平口水文站 $1978-$ 2012 年间逐日水面蒸发; 实测日流量资料来自水平口水文站 1978-2012 年间逐日平均流量和年洪水水文 要素摘录. 水平口流域上游有大河局、般若院和上关 3 座水库,选取这些水库 1978-2012 年间的放水资料, 模型计算中作为人流处理.

本文使用由美国太空总署 (NASA) 和国防部国家测绘局 (NIMA) 提供的 $90 \mathrm{~m} \times 90 \mathrm{~m}$ DEM 数据, 由美国 马里兰大学 $(\mathrm{UMD})$ 提供的全球 $1 \mathrm{~km}$ 精度的植被覆盖数据和由联合国粮农组织 (FAO) 和维也纳国际应用系 统研究所 (IIASA) 构建的世界土壤数据库 (HWSD) 提供的 $1 \mathrm{~km}$ 精度的土壤类型数据.

\section{2 栅格新安江模型}

\section{1 原理}

概念性新安江模型是根据湿润地区的产汇流规律总结提炼出来的流域水文模型. 该模型在我国的湿润 和半湿润地区广泛应用并取得成功在于其张力水蓄水容量以及自由水蓄水容量频率分布曲线的提出. 但是 这两条曲线没法直接反演到空间相关位置. 因此, 将概念性新安江模型栅格化处理的关键是将概念性模型 的频率分布曲线对应到空间栅格点. 研究表明, 流域的某些特征要素 (如地形曲率等) 具有空间频率分布. 这 为两条频率分布曲线的空间反演提供了基础.

栅格新安江模型选择地形指数来描述两种蓄水容量曲线的分布. 地形指数被普遍地用来描述地形和土 壤水空间分布的规律以及计算饱和汇流面积 ${ }^{[12]}$. 对比图 2 和图 3, 可以直观地看到河道附近地区的地形指 
数大多较大,这些区域的地下水埋深一般较浅, 即缺水量较少; 而在流域的上游以及距离河道较远的山坡地 区, 地形指数的值比较小, 一般缺水量较大. 这进一步说明了建立地形指数与相关土壤水含水层厚度函数关 系式的可行性.

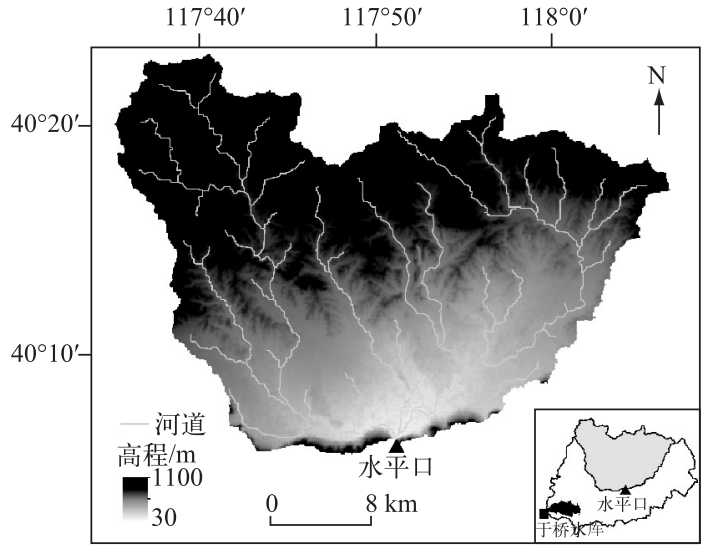

图 2 水平口流域的高程

Fig.2 DEM of Shuipingkou Basin

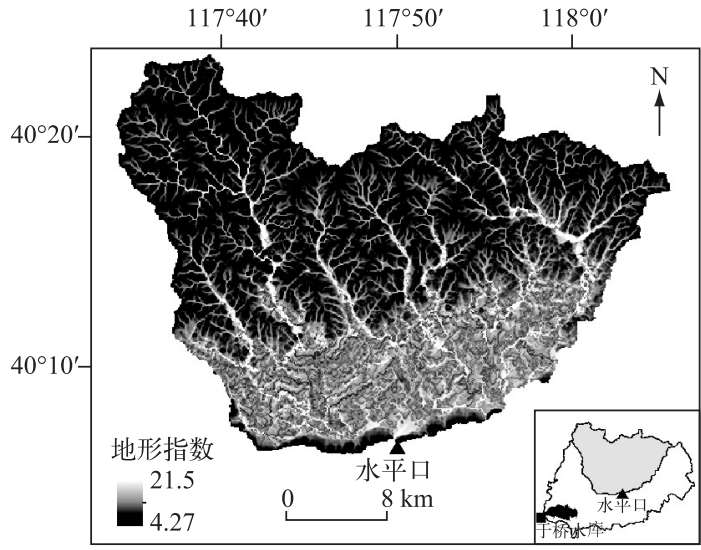

图 3 水平口流域的地形指数空间分布

Fig.3 Distribution of topographic index in Shuipingkou Basin

模型的计算是以栅格作为基本计算单元, 并假设栅格内的水文特性以及地形地貌特征是一致的. 模型 的计算结构如图 4 所示, 主要分为截留蒸散发计算、产流分水源计算以及汇流演算 3 个部分.

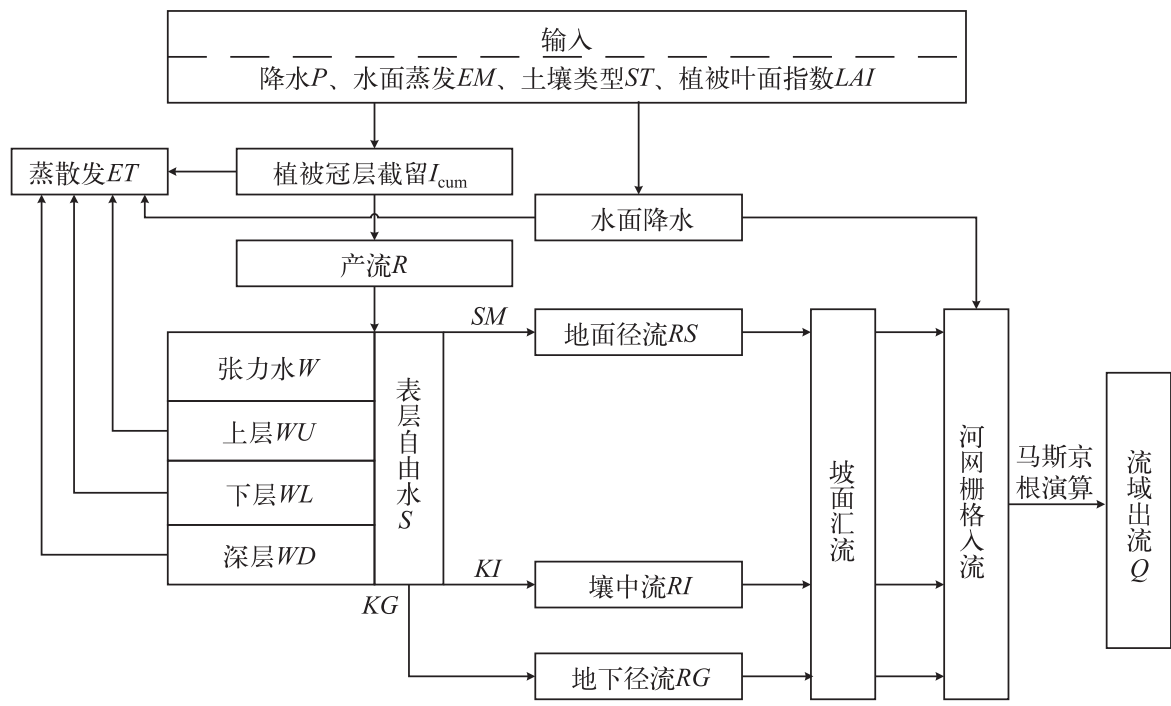

图 4 模型计算结构

Fig.4 Structure of the model

\section{2 参数}

模型中的产汇流参数 $W M 、 S M 、 K I$ 和 $K G$ 是需要获得空间分布的参数.

$W M$ 和 $S M$ 反映的是栅格单元土壤张力水和自由水的蓄水能力 ${ }^{[13]}$. 依据模型原理中的分析以及土壤水 的相关定义建立 $W M$ 和 $S M$ 的函数表达式:

$$
W M=\left(\theta_{\mathrm{fc}}-\theta_{\mathrm{wp}}\right) \cdot L_{\mathrm{a}} \cdot T W I
$$




$$
S M=\left(\theta_{\mathrm{s}}-\theta_{\mathrm{fc}}\right) \cdot L_{\mathrm{h}} \cdot T W I
$$

式中, $T W I$, 即 Topographic Wetness Index, 地形指数. $\theta_{\mathrm{fc}} 、 \theta_{\mathrm{wp}}$ 和 $\theta_{\mathrm{s}}$ 是由栅格内土壤类型确定的土壤特征参 数 ${ }^{[14]}$, 它们的空间分布是固定的. $L_{\mathrm{a}}$ 和 $L_{\mathrm{h}}$ 分别表示缺水土壤层的厚度和腐殖质层的厚度, 它们是通过地形指 数计算出来的.

$K G$ 反映的是基岩和土壤的渗透性, $K I$ 反映的是表层土的渗透性 ${ }^{[13]}$, 均与栅格内的土壤类型有关, 可以 借助土壤的空间分布关系来表示 $K G$ 和 $K I$ 的空间分布 ${ }^{[15]} . K G$ 和 $K I$ 是并联参数 ${ }^{[13]}$, 满足式 (3), 其中 $K G+K I$ 代表出流的快慢, $K G / K I$ 代表地下径流和壤中流的比. 模型率定计算过程中需要满足结构性约束 $K G+K I=$ 0.7. 符合实际意义, 在每次率定计算后, 都取所有栅格单元的 $K G+K I$ 均值与 0.7 做比较, 再调整, 使流域平均 $K G+K I$ 满足结构性约束.

$$
\left\{\begin{array}{c}
K G+K I=\left(\frac{\theta_{\mathrm{s}}}{\theta_{\mathrm{fc}}}\right)^{O C} \\
\frac{K I}{K G}=\frac{1+2\left(1-\theta_{\text {wp }}\right)}{R O C}
\end{array}\right.
$$

式中, $O C$ 为自由水出水综合影响因子, $R O C$ 为自由水出流校正系数.

而模型中汇流参数主要是集总参数. 汇流计算中, 日模计算采用线性水库和滞后演算法,对应单元流域 出口栅格 $t$ 时刻出流为:

$$
Q^{t+L a g}=Q^{t+L a g} \cdot C_{\mathrm{sch}}+\left(\sum_{j=1}^{k} Q_{s, j}^{t}+\sum_{j=1}^{k} Q_{i, j}^{t}+\sum_{j=1}^{k} Q_{g, j}^{t}\right)\left(1-C_{\mathrm{sch}}\right)
$$

式中, $Q_{s, j}^{t} 、 Q_{i, j}^{t} 、 Q_{g, j}^{t}$ 分别为单元流域内 $j$ 栅格 $t$ 时刻的地表、壤中和地下径流; $C_{\mathrm{sch}}$ 为河网消退系数; Lag 为河 网汇流滞时.

$C_{\text {sch }}$ 为线性水库与滞后演算法汇流参数 ${ }^{[13]}$, 反映全流域河网的调蓄能力. $C_{\mathrm{sch}}$ 控制着洪水的坦化程度.

次洪模型采用基于栅格的马斯京根法将 3 种产流和河道水流演算到流域出口. 以地表径流为例, 对应 栅格的 $t$ 时刻出流为:

$$
Q_{i+1}^{t+1}=\sum_{k}\left(C_{0} \cdot Q_{i}^{t}+C_{1} \cdot Q_{i}^{t+1}+C_{2} \cdot Q_{i+1}^{t}\right)_{k}+Q_{s, i+1}^{t+1}\left(1-f_{\mathrm{ch}}\right)
$$

式中, $f_{\mathrm{ch}}$ 为栅格地表径流汇人河道的比例.

$k_{\mathrm{m}}$ 和 $x_{\mathrm{m}}$ 是马斯京根法的汇流参数 ${ }^{[13]}$. 模型中按照径流成分差异分为 4 组参数. $k_{\mathrm{m}}$ 反映的是栅格间的汇流时 间,根据文献 $[16]$, 从河道、地表、壤中到地下,其取值大小依次减小. $x_{\mathrm{m}} 、 k_{\mathrm{mi}} 、 k_{\mathrm{mg}}$ 相对不敏感,主要调试 $k_{\mathrm{mch}}$ 和 $k_{\mathrm{ms}}$.

\section{3 结果与分析}

\section{1 参数率定}

从模型预处理求算出的水平口流域 $W M$ 和 $S M$ 空间分布可以很直观地看出来,越靠近河道的地方, 颜色 越深,表示特征蓄水容量越小(图 5、6).

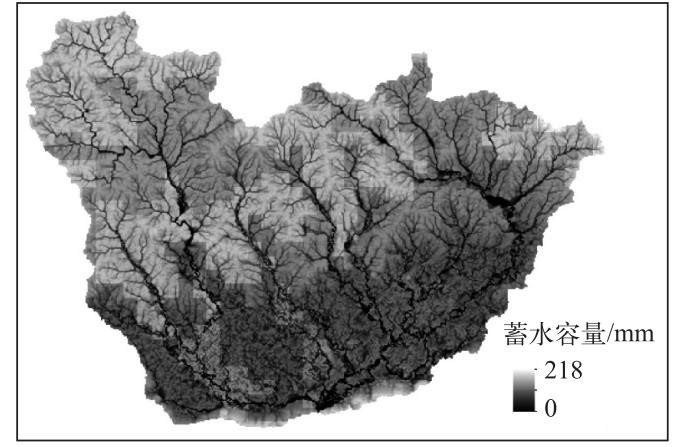

图 5 水平口流域张力水蓄水容量空间分布

Fig.5 Distribution of calculated tension water storage capacity in Shuipingkou Basin

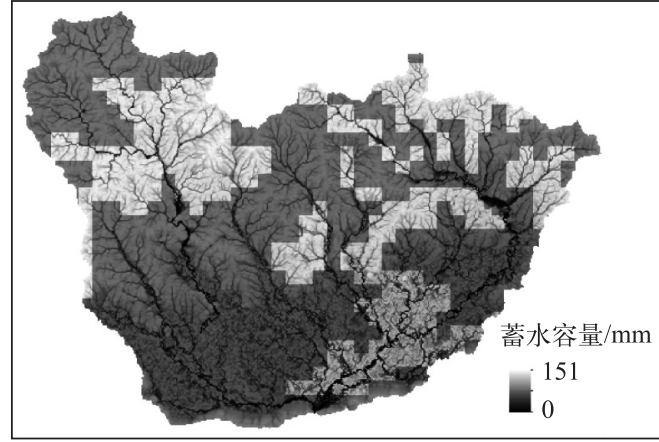

图 6 水平口流域自由水蓄水容量空间分布

Fig. 6 Distribution of calculated free water storage capacity in Shuipingkou Basin 
率定的模型参数如表 1 所示.

表 1 模型参数

Tab.1 The model parameters

\begin{tabular}{|c|c|c|c|}
\hline & 参数 & 参数意义 & 参数值 \\
\hline & $O C$ & 自由水出流综合影响因子 & 5 \\
\hline & $R O C$ & 自由水出流校正系数 & 0.3 \\
\hline & $C$ & 深层蒸散发折算系数 & 0.2 \\
\hline & $K$ & 蒸散发折算系数 & 1 \\
\hline & $L U M$ & 上层土张力水蓄水容量比例 & 0.167 \\
\hline & $L L M$ & 下层土张力水蓄水容量比例 & 0.5 \\
\hline & $L D M$ & 深层张力水蓄水容量比例 & 0.333 \\
\hline \multirow[t]{3}{*}{ 日模汇流参数 } & $C G$ & 地下水消退系数 & 0.998 \\
\hline & $C I$ & 壤中流消退系数 & 0.87 \\
\hline & $C_{\text {sch }}$ & 河网消退系数 & 0.8 \\
\hline \multirow[t]{8}{*}{ 次模汇流参数 } & $k_{\mathrm{mch}}$ & 河道水流马斯京根法参数 & 0.001 \\
\hline & $x_{\mathrm{mch}}$ & & 0.45 \\
\hline & $k_{\mathrm{ms}}$ & 地表径流马斯京根法参数 & 0.01 \\
\hline & $x_{\mathrm{ms}}$ & & 0.45 \\
\hline & $k_{\mathrm{mi}}$ & 壤中流马斯京根法参数 & 0.6 \\
\hline & $x_{\mathrm{mi}}$ & & 0.3 \\
\hline & $k_{\mathrm{mg}}$ & 地下径流马斯京根法参数 & 1 \\
\hline & $x_{\mathrm{mg}}$ & & 0 \\
\hline
\end{tabular}

\section{2 模拟结果}

选取 1978-2012 年间的 9 场典型洪水进行次洪模型模拟与预报,其中选定前 8 场洪水用来模拟率定次 洪模型参数,最后 1 场用来检验, 结果如表 2 所示.

表 2 次洪洪水模拟成果统计

Tab. 2 The simulation results

\begin{tabular}{ccccccc}
\hline 洪水编号 & $\begin{array}{c}\text { 实测径流深/ } \\
\mathrm{mm}\end{array}$ & $\begin{array}{c}\text { 计算径流深/ } \\
\mathrm{mm}\end{array}$ & $\begin{array}{c}\text { 径流深相对误差/ } \\
\%\end{array}$ & $\begin{array}{c}\text { 实测洪峰/ } \\
\left(\mathrm{m}^{3} / \mathrm{s}\right)\end{array}$ & $\begin{array}{c}\text { 计算洪峰/ } \\
\left(\mathrm{m}^{3} / \mathrm{s}\right)\end{array}$ & $\begin{array}{c}\text { 洪峰相对误差/ } \\
\%\end{array}$ \\
\hline 1978072422 & 117.1 & 118.2 & 1.0 & 881 & 856 & -2.8 \\
1978080808 & 67.0 & 61.0 & -8.9 & 780 & 805 & 3.3 \\
1978082615 & 127.4 & 126.1 & -1.1 & 1050 & 1070 & 2.1 \\
1984080920 & 18.6 & 20.0 & 7.6 & 450 & 477 & 6.1 \\
1994071215 & 23.3 & 27.1 & 16.4 & 302 & 298 & -1.3 \\
1996072219 & 10.8 & 14.5 & 34.4 & 181 & 178 & -1.4 \\
1996072805 & 38.9 & 40.6 & 4.3 & 458 & 499 & 9.0 \\
1996080217 & 76.7 & 62.4 & -18.5 & 689 & 672 & -2.4 \\
2012073013 & 111.0 & 101.0 & -9.0 & 252 & 233 & -7.5 \\
\hline
\end{tabular}

根据 GB/T 22482-2008《水文情报预报规范》可知:模型模拟结果中,水平口流域的 8 场洪水,径流深合 格率为 $87.5 \%$, 洪峰合格率为 100\%. 预报检验的 1 场洪水径流深和洪峰都合格. 9 场次洪无论是径流深误差 还是径流量误差都达到了乙等精度要求. 总的来说模型对峰大量大的洪水模拟效果要好于峰量偏小的洪水 过程.

从检验期 20121073013 号洪水模拟结果来看,仍有一定的误差, 初步分析如下: 模型流域的下垫面条件 如土壤、植被覆盖等随时间的变化没能显式地体现出来. 调研发现: 随着该地区水资源形势的日益严峻, 区 
域内的水利工程数量逐年增加. 同时, 当地居民修建了大量的水窝和小型拦设施. 这些人类活动使得流域的 产流量减小, 汇流时间变长,进而导致次洪模拟预报的洪峰峰值和洪量都偏小.

\section{3 产流面积变化分析}

受流域下垫面的影响,随着降雨的时空变化,流域的产流面积不断变化. 对流域产流面积变化规律进行 研究和定量描述, 对确定流域产流量有重要的意义. 传统的概念性新安江模型为分散性结构, 受其根据经验 总结提出的蓄水容量分布曲线的局限性只能得出流域出口断面的流量过程, 无法对流域面上具体点或区域 的水文过程进行反演和研究. 栅格新安江模型在概念性新安江模型的基础上, 显式地构建了栅格单元上蓄 水容量与土壤类型、植被覆盖以及地形坡度等下垫面特征的关系, 结合降水过程, 能反映水文过程在时空尺 度上的变化.

选取 1978080808 次洪水过程为例进行分析,本次洪水的降水空间分布基本均匀. 图 7 表示的是这场次 洪不同时刻空间各个栅格的蓄水状态, 栅格值越接近 1 表示栅格越接近蓄满的状态. 在降雨初期 (图 7a), 流 域南部的地势较低的区域以及河道附近随着降雨过程的进行逐渐呈现蓄满的状态. 说明这片地区发生洪水 灾害的可能性较大, 应该加强巡视. 随着降水过程的进行 (图 7b), 降水强度的增加, 产流区域面积也在逐渐 变大, 最后达到全流域最大的蓄满状态 (图 7c), 此时流域的东南大部分地区以及西北的部分地区达到蓄满 状态, 发生洪灾的可能性较大. 通过图 7 可以直观地看出空间栅格不同时刻土壤的蓄水状态, 这对流域内的 防洪减灾有一定的参考价值.
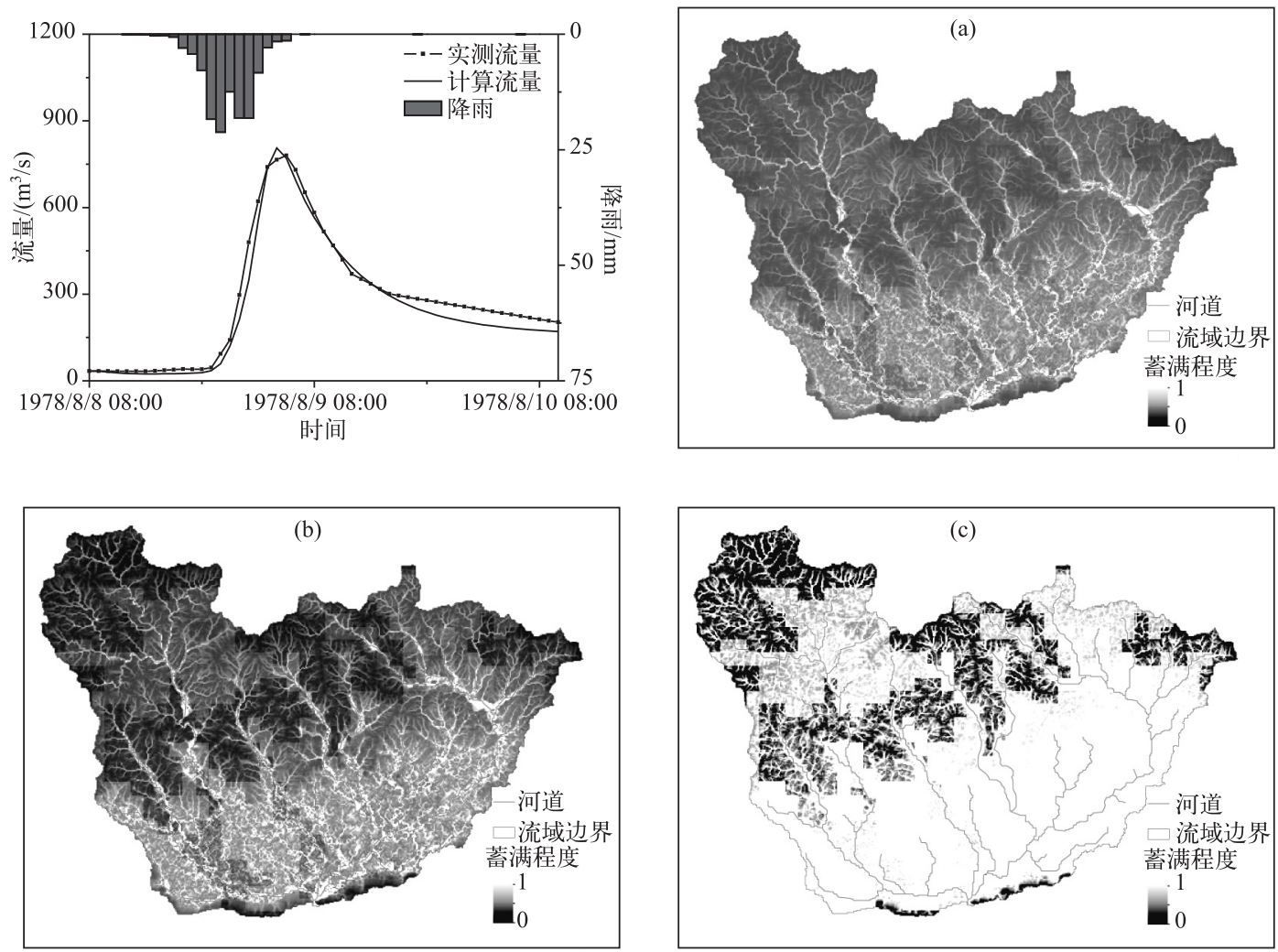

图 71978080808 号洪水降水径流模拟过程和不同时刻栅格蓄水状态空间分布 ( $\mathrm{a} \sim \mathrm{c}$ 表示随着降水的进行,流域逐渐蓄满的变化过程)

Fig.7 The result and soil state distribution of No. 1978080808 Flood 


\section{4 结语}

本文使用柵格新安江模型在于桥水库流域的水平口地区进行应用,模型较好地反映了产流面积的时空 变化, 达到理想的计算精度. 初步验证了该模型在半湿润地区的适用性. 模型的结构和参数仍然需要进一步 的研究和调整来提高模型的适用性、体现流域内人类生活生产活动的影响. 总的来说,栅格新安江模型是水 文模型精细化发展的一种趋势, 是传统水文模型理论与地理信息技术结合的产物, 模型除对自身结构参数 进行研究调整外,还需与山坡水文学和地理信息技术研究的最新进展进行跟进.

致谢: 感谢黄鹏年、钟栗、孙如飞师兄对本研究提供的帮助和宝贵建议.

\section{5 参考文献}

[ 1 ] Li Zhilin, Zhu Qing. Digital elevation model. Wuhan: Wuhan University Press, 2001 (in Chinese). [ 李志林, 朱庆. 数字 高程模型. 武汉: 武汉大学出版社, 2001.]

[ 2 ] Wang Zhonggen, Liu Changming, Zuo Qiting et al. Constructing distributed hydrological model based on DEM. Progress in Geography, 2002, 21(5): 430-439 (in Chinese with English abstract). [王中根, 刘昌明, 左其亭等. 基于 DEM 的分 布式水文模型构建方法. 地理科学进展, 2002, 21(5): 430-439. ]

[ 3 ] Huang Ping, Zhao Jiguo. Study on watershed distributed hydrological model and its application prospect. Journal of China Hydrology, 1997, (5) : 5-9 (in Chinese with English abstract). [ 黄平, 赵吉国. 流域分布型水文数学模型的研究及应 用前景展望. 水文, 1997, (5) : 5-9.]

[ 4 ] Hao Zhenchun, Su fengge. Study on distributed monthly hydrological model and its application in Huaihe River basin. Advances in Water Science, 2000, 11(1):36-43(in Chinese with English abstract). [ 郝振纯, 苏凤阁. 分布式月水文模型 研究及其在淮河流域的应用. 水科学进展, $2000,11(1): 36-43$. ]

[ 5 ] Liu Zhiyu, Xie Zhenghui. Improvement of the TOPKAPI model and its application in the Huaihe River basin flood simulation study. Journal of China Hydrology, 2003, 23(6) : 1-7(in Chinese with English abstract). [刘志雨, 谢正辉. TOPKAPI 模型的改进及其在淮河流域洪水模拟中的应用研究. 水文, 2003, 23(6)：1-7. ]

[6 ] Xiong Lihua, Guo Shenglian, Tian Xiangrong. Distributed hydrological model based on DEM and its application. Advances in Water Science, 2004, 15(4): 517-520(in Chinese with English abstract). [熊立华, 郭生练, 田向荣. 基于 DEM 的 分布式流域水文模型及应用. 水科学进展, 2004, 15(4): 517-520.]

[ 7 ] Li ZJ, Zhang K. Comparison of three GIS-based hydrological models. Journal of Hydrologic Engineering, 2008, 13 (5): 364-370

[ 8 ] Yao Cheng. Development and application of grid-based distributed Xinanjiang Model [Dissertation]. Nanjing: Hohai University, 2007 (in Chinese with English abstract). [姚成. 基于栅格的分布式新安江模型构建与分析 [ 学位论文]. 南 京: 河海大学, 2007.]

[ 9 ] Yao C, Li Z, Bao H et al. Application of a developed Grid-Xinanjiang model to Chinese watersheds for flood forecasting purpose. Journal of Hydrologic Engineering, 2009, 14(9) : 923-934.

[10] Yao Cheng, Ji Yiqu, Li Zhijia et al. Parameter estimation and application of grid-based Xin'anjiang model. Journal of Hohai University (Natural Sciences), 2012, 40(1) : 42-47(in Chinese with English abstract). [姚成, 纪益秋, 李致家等. 栅格型新安江模型的参数估计及应用. 河海大学学报: 自然科学版, 2012, 40(1): 42-47.]

[11] Yao Cheng, Zhang Yuxia, Li Zhijia. Application and comparison of cell-to-cell diffusion wave and Muskingum routing methods. Journal of Hohai University (Natural Sciences), 2013, (1):6-10(in Chinese with English abstract). [姚成, 章 玉霞, 李致家. 扩散波与马斯京根法在栅格汇流演算中的应用比较. 河海大学学报: 自然科学版, 2013, (1): 6-10.]

[12] Beven KJ, Kirkby MJ. A physically based, variable contributing area model of basin hydrology/Un modèle à base physique de zone d'appel variable de l'hydrologie du bassin versant. Hydrological Sciences Journal, 1979, 24(1) : 43-69.

[13] Zhao Renjun, Wang Peilan. Study on parameters of Xinanjiang model. Journal of China Hydrology, 1988, 8( 6) : 2-9( in Chinese with English abstract). [赵人俊, 王佩兰. 新安江模型参数的分析. 水文, 1988, 8(6): 2-9.]

[14] Rui Xiaofang ed. Principles of hydrology. Beijing: China Water \& Power Press, 2004(in Chinese). [芮孝芳. 水文学原 理. 北京: 中国水利水电出版社, 2004. ]

[15] Koren VI, Smith M, Wang D et al. Use of soil property data in the derivation of conceptual rainfall-runoff model parameters//15th Conference on Hydrology, Long Beach, American Meteorological Society, Paper. 2000.

[16] Wu Xianfeng. Research on distributed watershed hydrological model: a case study of Lushi basin in the Yellow River[Dissertation]. Beijing: Beijing Normal University, 2003(in Chinese with English abstract).[吴险峰. 分布式流域水文模型 研究——黄河小花间卢氏以上流域案例研究 [学位论文]. 北京: 北京师范大学, 2003. ] 